\title{
UN ESCRITORIO DE CAMPAÑA ANGLO-CHINO ADQUIRIDO EN FILIPINAS Y TRAIIDO A ASTURIAS EN LA DÉCADA DE 1880
}

\author{
AN ANGLO-CHINESE CAMPHOR CAMPAIGN WRITING CHEST BROUGHT TO \\ ASTURIAS FROM PHILIPPINES IN THE 1880S
}

Ángela Ferreira Martínez* Ángel José Cañedo López ${ }^{* *}$ Investigadores independientes

\section{Resumen}

Una cómoda escritorio de campaña de estilo Regency fabricada en madera de alcanfor por ebanistas chinos establecidos en Filipinas. Su dueño fue don Ramón Martínez-Labiarón, canónigo magistral de la Catedral de Manila que la trae como parte de su equipaje en el viaje de regreso a Asturias tras el terremoto que asoló Manila en 1880.

El descubrimiento de esta pieza en Grandas de Salime, un pequeño pueblo asturiano de difícil acceso en el siglo XIX es un ejemplo de penetración de estilos de muebles extranjeros de alta calidad por los puertos marítimos del norte de España.

Palabras clave: cómoda escritorio, anglo - chino, estilo Regency, Asturias, Filipinas.

\section{Abstract}

A Regency style campaign chest of drawers desk made in Kamagong wood by Chinese cabinetmakers established in the Philippines. Its owner was Mr. Ramon Martinez-Labiarón, canon of the Cathedral of Manila. He brings it as part of his luggage when returns to Asturias after the earthquake that devasted Manila in 1880.

The discovery of this piece in Grandas de Salime, a small Asturian village with difficult access in the 19th century is an example of the penetration of high-quality foreign furniture styles thought the maritime ports of the North of Spain.

Key words: chest of drawers writing desk, Anglo-Chinese, regency furniture, Asturias, Philippines. 


\section{Introducción}

La complejidad de abordar el estudio de un mueble realizado en los territorios de ultramar viene dada, en este caso, debido a que los ebanistas que los realizan reproducen fielmente los estilos de las metrópolis, y salvo por el uso de determinadas maderas, a veces, una simple sustitución de las bocallaves hace muy difícil determinar su origen, lo que, sumado al carácter mueble de los elementos de estudio, dificulta la clasificación de éstos al no estar documentada su procedencia. A veces la calidad del mueble realizado por ebanistas fuera del continente, en las colonias, supera a la que se podía encontrar en Europa.

Un ejemplo de la fina ebanistería colonial del siglo XVIII, son una pareja de excepcionales cómodas de sacristía realizadas en La Habana, cuya factura, calidad y uso de la caoba en fechas tempranas, las ponen en línea con lo mejor de la producción de mobiliario que se pudiese encontrar en Europa, y que, de no estar perfectamente documentadas cuando fueron vendidas en subasta ${ }^{1}$, y existir otra pareja similar en la sacristía de la iglesia de San Francisco en La Habana para cotejarlas, sería muy complicado saber cuál fue su lugar de producción.

Esto también es debido a la amplia difusión de los modelos de mobiliario y diseño de interiores gracias a la cantidad de pattern books ${ }^{2}$ que se publican durante la segunda mitad del siglo XVIII y primera del siglo XIX, y que tienen su máximo referente en los diseños de Thomas Sheraton en su The Cabinet maker and upholstered book. ${ }^{3}$

En el caso de esta cómoda escritorio, no solamente hemos tenido la suerte de poder tener una información fidedigna desde su adquisición hasta la actualidad, sino que también la particularidad de la trasera que tiene el mueble hace que podamos identificar su lugar de producción. Sin ese dato, sólo podríamos conjeturar que es un mueble realizado en Asia en estilo Regency pero sin saber si en territorio portugués, inglés, o español. Existen modelos tipológicamente iguales en los que, por fortuna, se encuentran las etiquetas del fabricante o del ebanista y nos dan orígenes tan distintos, como Macao, Cantón o Batavia.

\section{El propietario y los posibles itinerarios del mueble hasta llegar a Asturias}

El propietario del mueble fue don Ramón Martínez-Labiarón Villabrille (Grandas de Salime, 1821 - Ídem, 30 de noviembre de 1884) (fig.1), que ostentó una sucesión de cargos a lo largo de su carrera eclesiástica en la Santa Iglesia Metropolitana de Manila ${ }^{4}$, ciudad a la que llegó embarcado en la fragata Victoria, que había partido desde el puerto de Cádiz en marzo de 1848, a través del cabo de Buena Esperanza. Tras cinco meses de viaje, llega a la isla el 25 de julio del mismo año, donde se instala durante más de treinta años de vida eclesiástica en el cabildo catedralicio de la colonia española.

Ha sido fundamental para este estudio el rastreo de información del prelado en el archivo familiar de los Martínez Guzmán, el registro civil de Grandas de Salime y la sección del Archivo Histórico Nacional dedicado a las posesiones españolas en Ultramar y dentro del mismo, a Filipinas; así como los estudios del 
doctor Roberto Blanco sobre el cabildo catedralicio de Manila durante los años en los que Martínez-Labiarón desarrolló su actividad eclesiástica en la isla.

Gracias a la documentación consultada, tenemos constancia que, durante la década de 1860, Ramón Martínez se implica en la defensa del clero secular diocesano ante los abusos del patronato siguiendo las directrices de Pedro Peláez ${ }^{5}$, en tiempos del arzobispo Gregorio Melitón Martínez Santa Cruz, que ostentó el poder de la archidiócesis entre 1861 y 1875. Dicho arzobispo tenía en alta estima a nuestro protagonista ya que lo cita como "sacerdote instruido y de buenas costumbres"6; no es de extrañar, puesto que el canónigo había nacido en el seno de una acomodada familia del occidente de Asturias, emparentada con Juan Alonso Villabrille y Ron, uno de los escultores asturianos más sobresalientes del Barroco español. No obstante, Melitón menciona en la misma carta que "no hay más que otros tres condecorados con grado mayor al de Laviarón" dentro del cabildo catedralicio de Manila. ${ }^{7}$

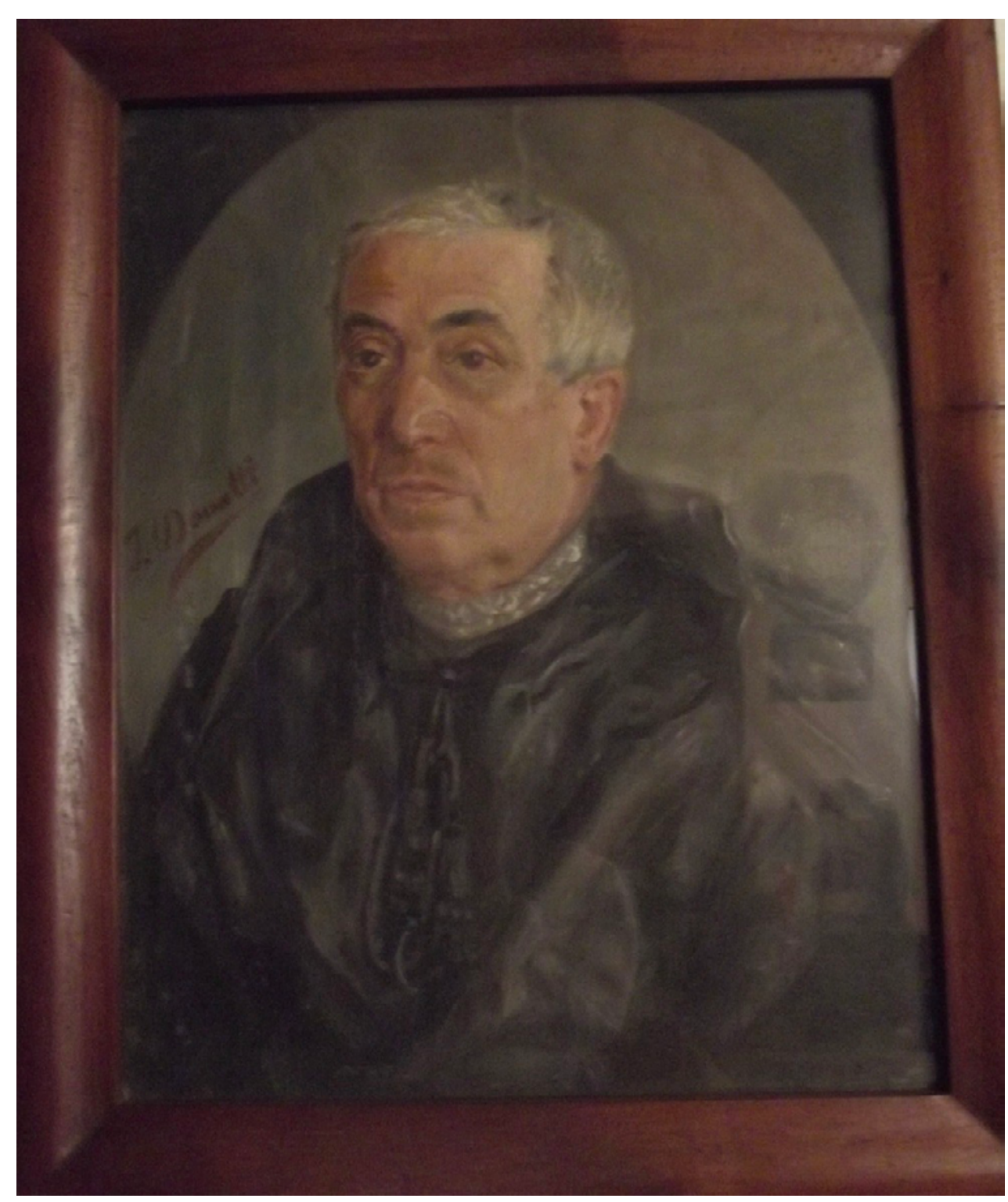

Fig. 1. Retrato de Ramón Martínez-Labiarón Villabrille. J. Donatti, hacia 1870. Óleo sobre lienzo. 
El 3 de junio de 1863 se produce un fuerte terremoto en Manila, que destruye el ayuntamiento, el Palacio del Gobernador y prácticamente la totalidad de la catedral, mientras en su interior se estaba produciendo la celebración de Corpus Christi. El resultado del seísmo fue el fallecimiento de siete eclesiásticos catedralicios entre los que destaca el citado Pedro Peláez; Martínez-Labiarón sobrevive, pero su salud queda irremediablemente dañada. ${ }^{8}$

Un nuevo seísmo asola Manila en $1880^{9}$ y nuestro protagonista que ya tiene 60 años, solicita una licencia para desplazarse a la península a restablecer su deteriorada salud. ${ }^{10}$ Es posible que ante el clima de crispación política que desembocaría poco después en la Batalla de Cavite, decidiera regresar a su hogar. En este viaje de vuelta a España realizado en 1882, trae consigo un conjunto de enseres, entre los que destaca el canterano objeto de este estudio, un calvario hispano filipino de marfil enmarcado en ébano, una colcha de seda con decoración bordada de animales y elementos vegetales, un cáliz de oro, varias casullas y un retrato al óleo. El mueble fue ubicado en el actual comedor de la casa, en cuyo interior se guardaba parte del ajuar anteriormente mencionado y ha permanecido en su sitio desde la llegada del canónigo hasta la actualidad. ${ }^{11}$

La teoría más plausible para la entrada del presbítero en la península ibérica en su viaje de regreso a su localidad natal es por el puerto de Barcelona a través del canal de Suez. El canal de Suez se había inaugurado con gran pompa y solemnidad en el año 1869 siendo España uno de los grandes beneficiados de esta nueva ruta marítima con la que podía acortar el viaje a Filipinas en varias semanas. ${ }^{12}$ La nueva Ley de Puertos ${ }^{13}$ promulgada en mayo de 1880 clasifica en su artículo 16 el puerto de Barcelona como de primer orden, por lo que no es ni mucho menos atrevido asegurar que don Ramón Martínez desembarcara en España a través del citado puerto de Barcelona.

Martínez-Labiarón no regresaría jamás a Manila, ya que el 16 de mayo de 1883 se le concede una nueva prórroga de seis meses para que siga permaneciendo en la península a fin de poder restablecer su salud; finalmente fallece por una angina de pecho el 30 de noviembre de $1884 .^{14}$

La preparación del viaje de regreso a España por parte de don Ramón Martínez aconteció tras la adquisición del canterano a manos de su posible primer propietario, don Emilio Pazos-Vela Hidalgo (Ferrol, 26 de enero de 1839 - Manila, 29 de agosto de 1880), (fig.2) contador de navío de $1^{\mathrm{a}}$ clase del cuerpo administrativo de la Armada Española y profesor de la Escuela Naval Flotante de Ferrol.

Emilio Pazos pertenece a una saga de marinos de la Armada Española, varios de ellos desplazados a colonias como el caso de su padre, don Pío Pazos Barcáiztegui, que llegó a ser capitán de la Real Armada Española, pasando gran parte de su vida militar en La Habana; y dos de sus hermanos, don Pío Pazos Vela-Hidalgo que fue destinado como teniente en Filipinas entre 1863 y 1868, cuando se fecha su regreso a España, donde terminó siendo nombrado capitán de la Arma de Infantería ${ }^{15}$; y don Ángel Pazos Vela-Hidalgo, coronel y gobernador de las islas Marianas hasta su brutal asesinato en Guam en 1884, en ese momento parte de los territorios de la Corona española.

La atribución de la adquisición del mueble por parte de MartínezLabiarón a Emilio Pazos es una hipótesis basada en la coincidencia de ambos en 
los mismos años en Filipinas y el no haber encontrado ningún otro funcionario civil, militar o marino, con el apellido Pazos que estuviese residiendo en esta colonia del Pacífico durante ese periodo. Los muebles de estas características y calidad sólo eran utilizados por las élites militares marítimas en sus desplazamientos y para el amueblamiento de camarotes y salones de la oficialidad en los buques, que eran una copia reducida de los ajuares que podría uno encontrarse en una habitación de una gran casa en tierra firme. ${ }^{16}$

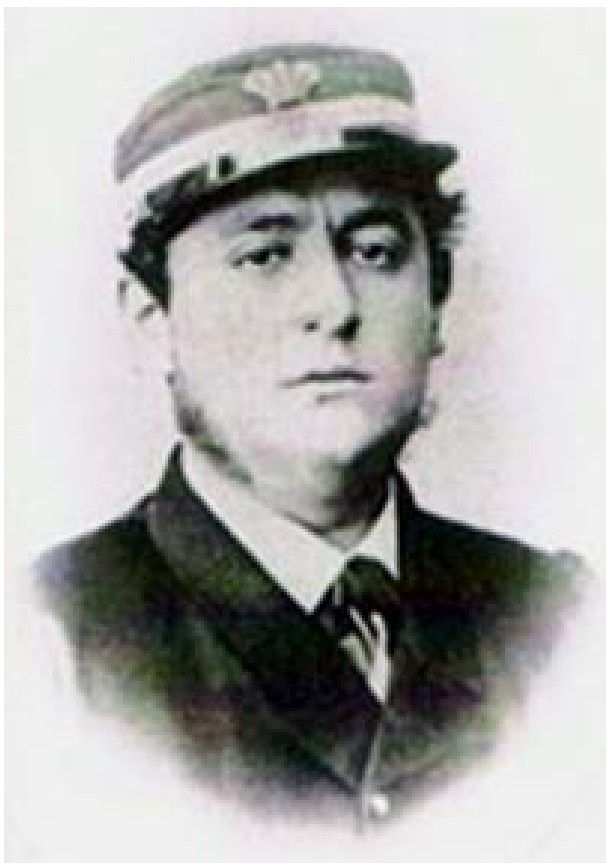

Fig. 2. Retrato de Emilio Pazos y Vela Hidalgo. Autor desconocido. Copia fotográfica. Imagen extraída con autorización de: Juan Bruno Zayas de la Portilla. Diecisiete generaciones del Gran Almirante. Presencia y trayectoria de su descendencia cubana. Sinopsis genealógica, (XII.2). https:// zayaspublishing.com/diecisiete-generaciones-delgran-almirante/ (consultado el 31/05/2021).

\section{Análisis del canterano}

El hallazgo de este mueble en una casa tradicional de la localidad de Grandas de Salime, en el occidente de Asturias, fue tan sorprendente como casual. No es habitual encontrar muebles realizados por ebanistas chinos siguiendo estilos de mobiliario inglés, que puedan rastrearse desde su lugar de producción, la adquisición de su segundo propietario en la provincia de Filipinas, y seguir su viaje hasta la ubicación actual.

El fortuito hallazgo fue a raíz del estudio de otra pieza que era un calvario hispano-filipino de finales del siglo XVIII o principios del XIX realizado en marfil policromado y enmarcado en un expositor de madera de ébano y marfil (fig.3). El calvario se hallaba guardado dentro del mueble a estudio que, a simple vista, y relacionándolo con otras piezas que guardaba en su interior de claro origen asiático, como una magnífica colcha en seda bordada con motivos de flores, plantas y pájaros de manufactura china (fig.4), hacía sospechar que el mueble era una pieza traída de las posesiones españolas en Asia.

La pieza es una cómoda escritorio de campaña de estilo Regency ${ }^{17}$ (18111820) y realizada aproximadamente entre 1830-1840 en madera de alcanfor y con una trasera en una madera que, en un principio, por la veta y su dureza se identificó como Lignum vitae $^{18}$, pero que resulto ser madera de kamagong (fig.5). 

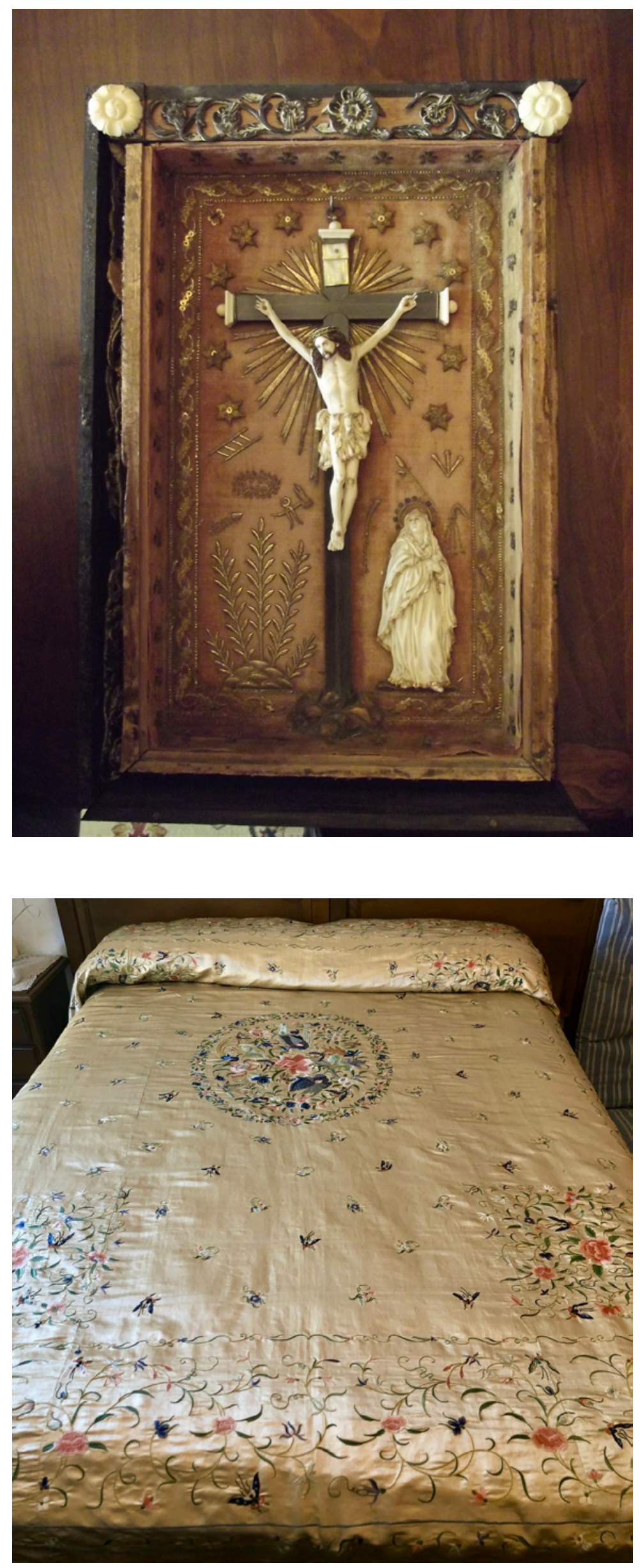

Fig. 3. Calvario. Anónimo (Taller hispano filipino), c. 1.800. Figuras: marfil de elefante, vidrio, cabello humano, pigmentos. Cruz: madera de palosanto, marfil. Escaparate: madera de ébano, marfil, seda, hilo de oro y lentejuelas. Antigua casa de Ramón MartínezLabiarón, Grandas de Salime (Asturias). Foto: Ángela Ferreira Martínez.
Fig. 4. Colcha. Cantón, segunda mitad del siglo IXI. Seda bordada. Antigua casa de Ramón MartínezLabiarón, Grandas de Salime (Asturias). Foto: Ángela Ferreira Martínez. 


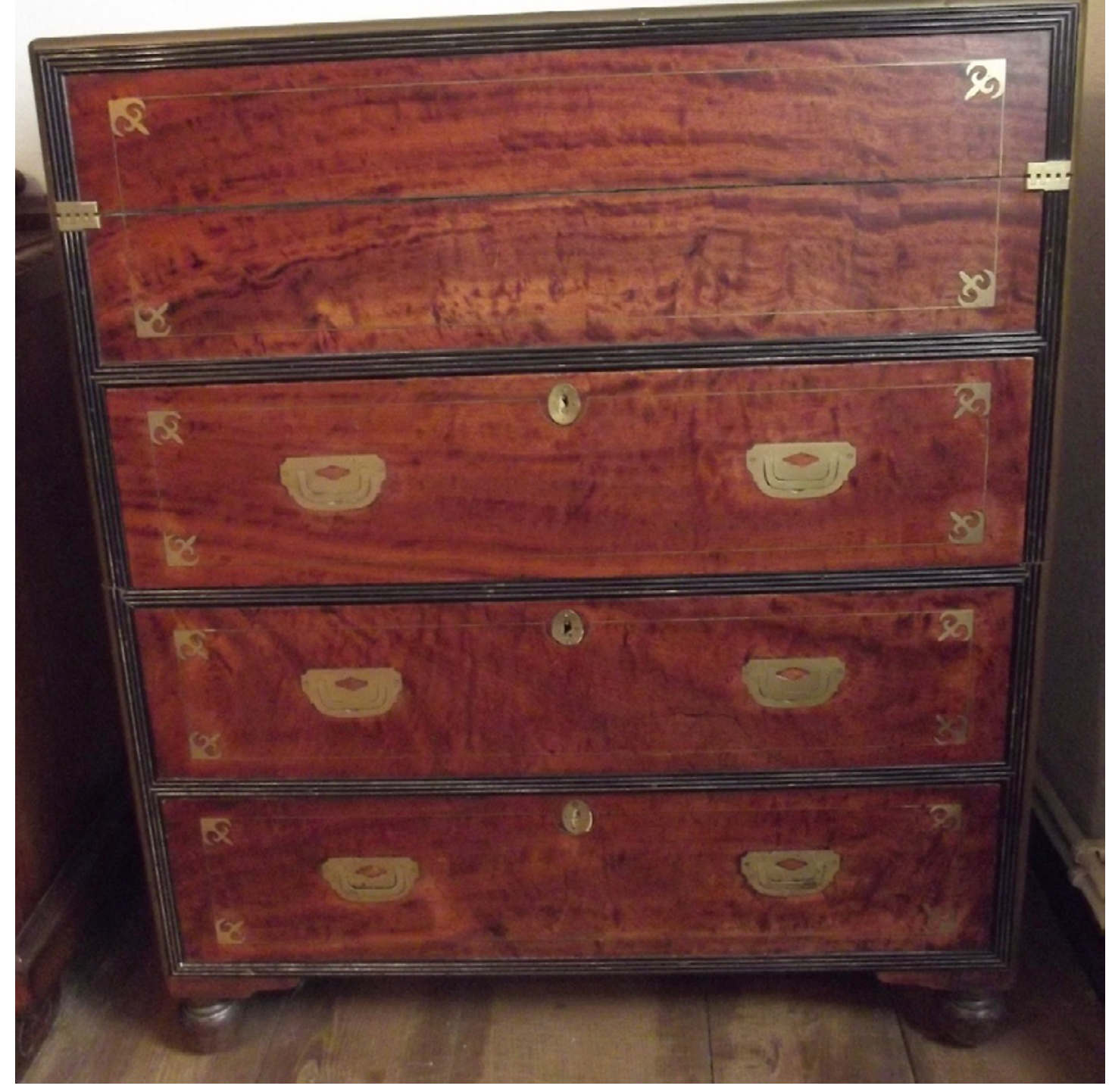

Fig. 5. Cómoda escritorio de campaña. Filipinas, c. 1840. Madera de alcanfor, madera de kamagong y metal. 103x86x48 cm. Antigua casa de Ramón Martínez-Labiarón, Grandas de Salime (Asturias). Foto: Ángela Ferreira Martínez.

Sostenemos la datación de 1830-1840 puesto que su decoración y tipología constructiva, encaja con el tipo de mobiliario inglés realizado en esa década; sobre todo en territorios de ultramar, dónde los estilos decorativos perviven más tiempo que en la metrópoli. Las fechas de llegada a España y muerte de su propietario hacen imposible que el canterano fuese una pieza realizada al gusto del Regeny Revival, que se desarrolló en Inglaterra a finales del XIX ${ }^{19}$.

Se divide en dos piezas con cuatro asas laterales para facilitar su transporte. La parte de arriba del cuerpo superior es abatible desplazándose hacia el frente, convirtiéndose en un escritorio con tablero inclinado y fuertes bisagras que lo sustentan. Al abrirlo deja a la vista tres pequeños cajones en el frente, con tiradores embutidos de latón y con caracteres numéricos chinos en el reverso de éstos (fig.6). La balda de escritura se abate en dos partes dejando al descubierto compartimentos secretos, casilleros, archivadores y un armarito central con puerta (fig.7). 


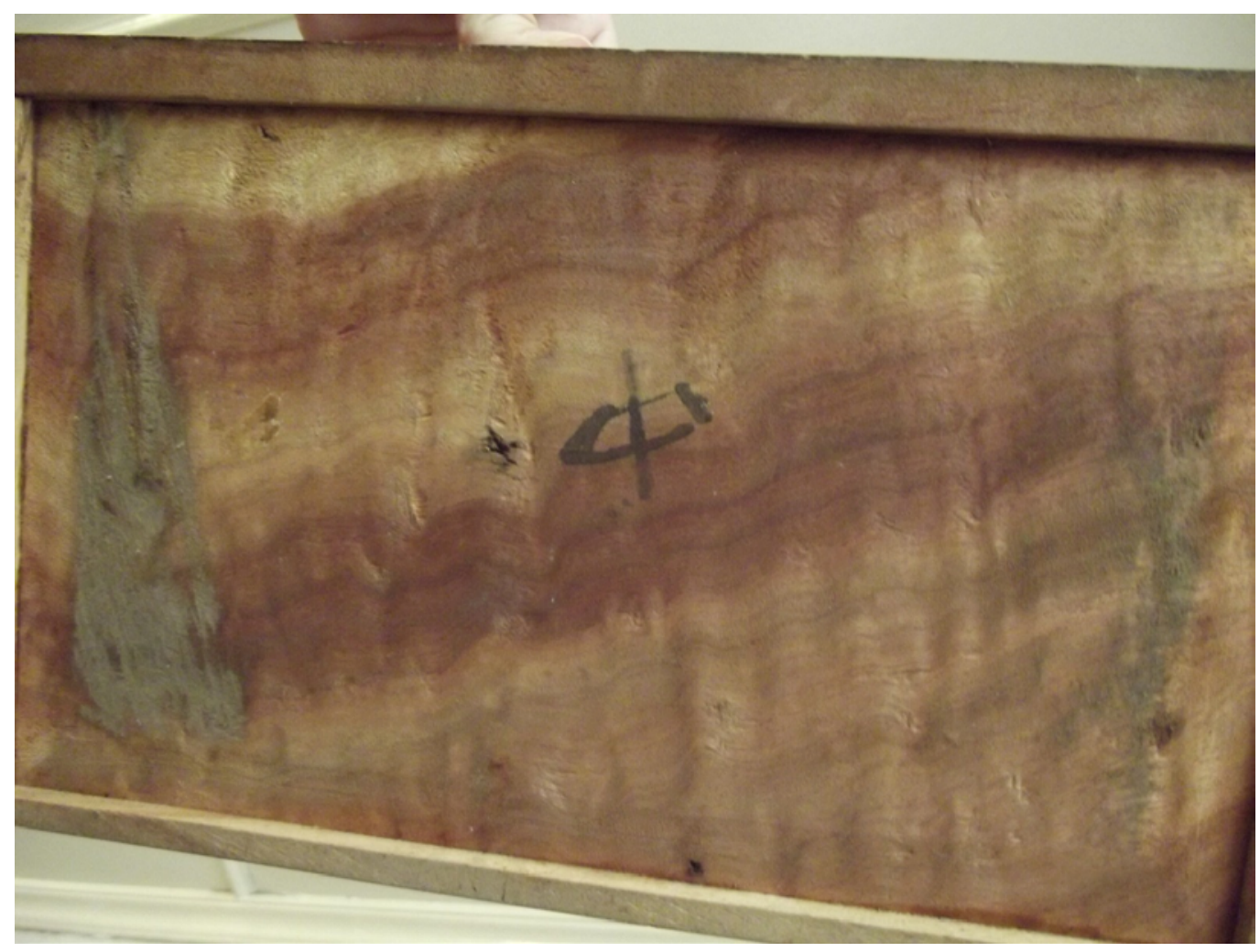

Fig. 6. Zhong. Carácter en chino mandarín, escritura cursiva. Realizado en tinta negra sobre el reverso del fondo de uno de los cajones de la cómoda escritorio. El carácter Zhong se traduce, en este caso, como: en el medio. Casa de Ramón Martínez-Labiarón, Grandas de Salime (Asturias). Foto: Ángela Ferreira Martínez.

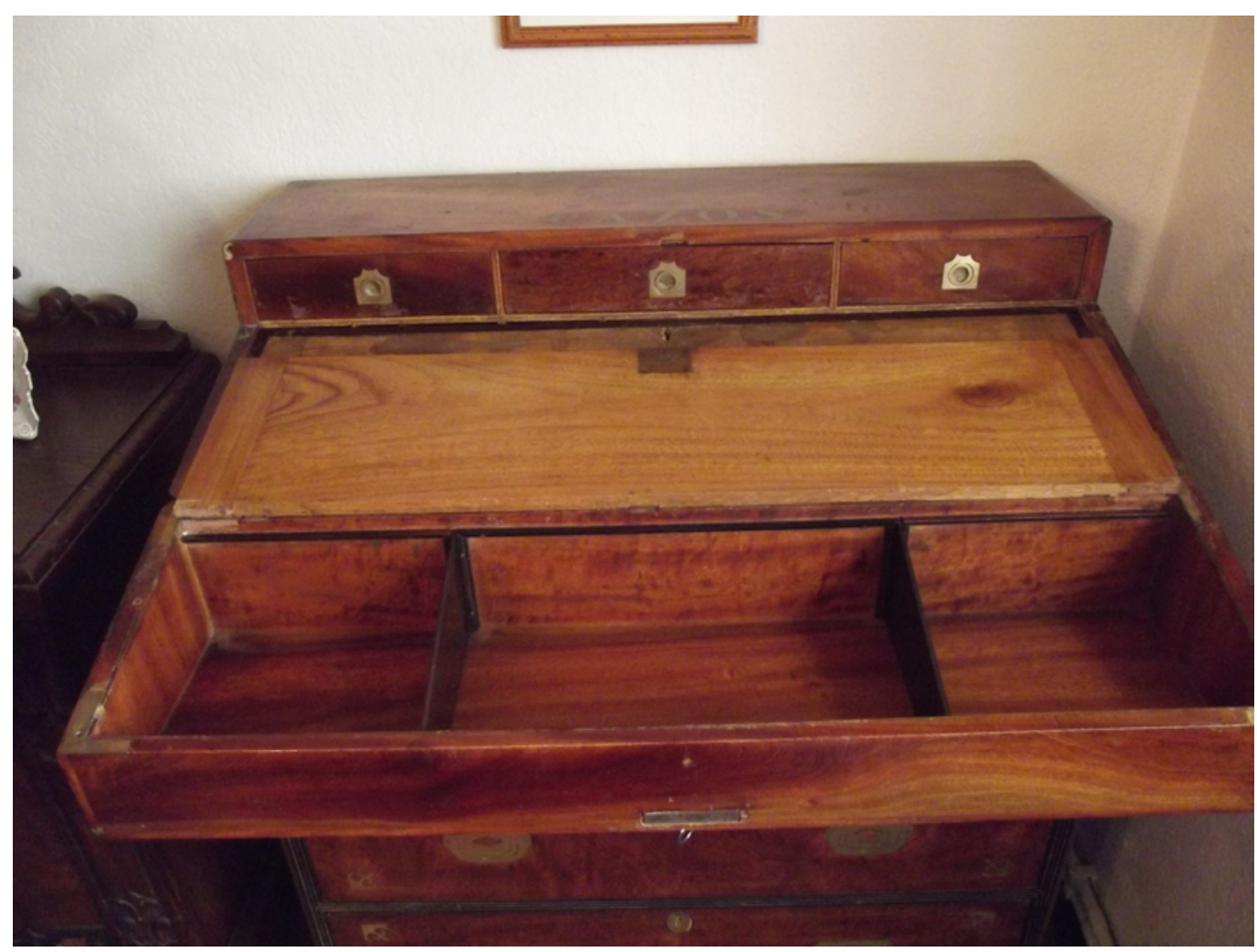

Fig. 7. Detalle del escritorio con la parte superior abierta. Antigua casa de Ramón Martínez-Labiarón, Grandas de Salime (Asturias). Foto: Ángela Ferreira Martínez. 
Completa el mueble un registro de tres cajones al frente, cerradura central y tiradores de latón embutidos. Los cajones, así como la parte superior que se abate, tienen una decoración perimetral de cenefa en latón inserta en la madera de alcanfor que remata en las cuatro esquinas con una estilización de palmeta o flor de lis, característica del estilo Regency inglés. En el sobre, aparece el nombre "PAZOS" con letras del mismo material atornilladas a la madera junto con una bocallave de cerradura con su llave original que cierra la zona de escritura (fig.8). Todo el mueble va reforzado por una lista perimetral en latón que protege los bordes del mueble de golpes en los traslados.

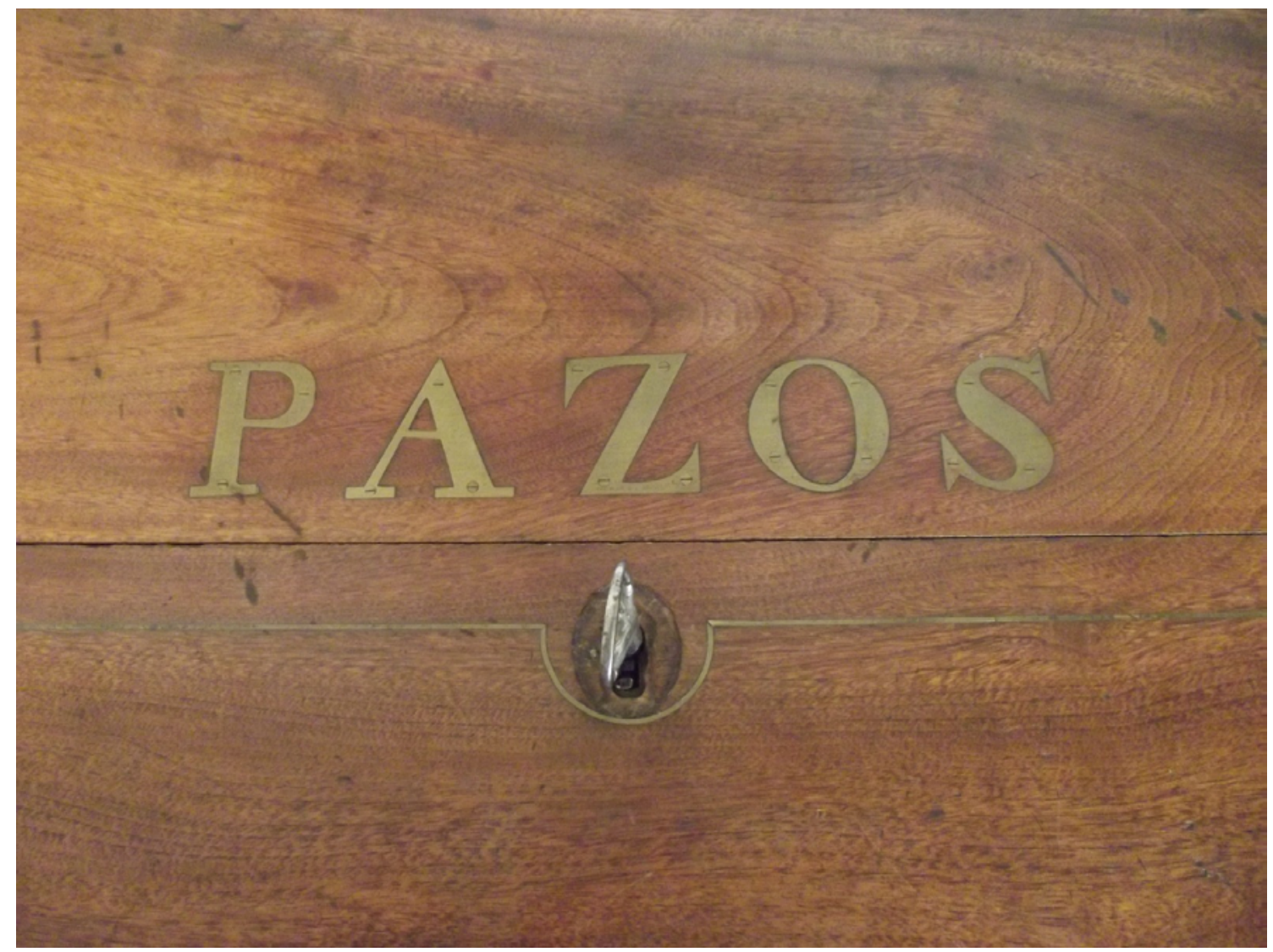

Fig. 8. Inscripción del apellido Pazos en latón recortado, embutido y atornillado sobre la tapa abatible que cierra el escritorio.

Una de las singularidades del mueble es su trasera realizada en madera de kamagong, lo que ha permitido catalogar la pieza como realizada por ebanistas chinos afincados en territorio de Filipinas y no una pieza manufacturada en las colonias británicas de Hong Kong, Cantón o en la portuguesa de Macao. Lugares éstos donde habitualmente se realizaba todo tipo de mobiliario en estilo inglés para su exportación (fig.9).

La madera de kamagong es endémica de Filipinas y era la utilizada para el mobiliario que se realizaba para las familias de la aristocracia colonial, terratenientes y altos funcionarios de la administración. La confusión con la madera de Lignum vitae es fácil, ya que tienen un grano, dureza, y vetas bastante similares, siendo igualmente difícil de trabajar y tóxica por contacto con el polvo 
resultante de pulirlas o cortarlas ${ }^{20}$. También hemos comprobado al hacer un barrido de piezas del siglo XIX, realizadas con esta madera, en anticuarios y casas de subastas filipinas que son bastante escasos, pero que el realizar modelos de estilos ingleses no era inhabitual ya que no solamente el Regency era copiado, sino que también se reproducían en estilo Sheraton $^{21}$, siendo curiosamente esta provincia española en Asia, donde se manufacturaba mobiliario en estilos foráneos para el mercado anglosajón.

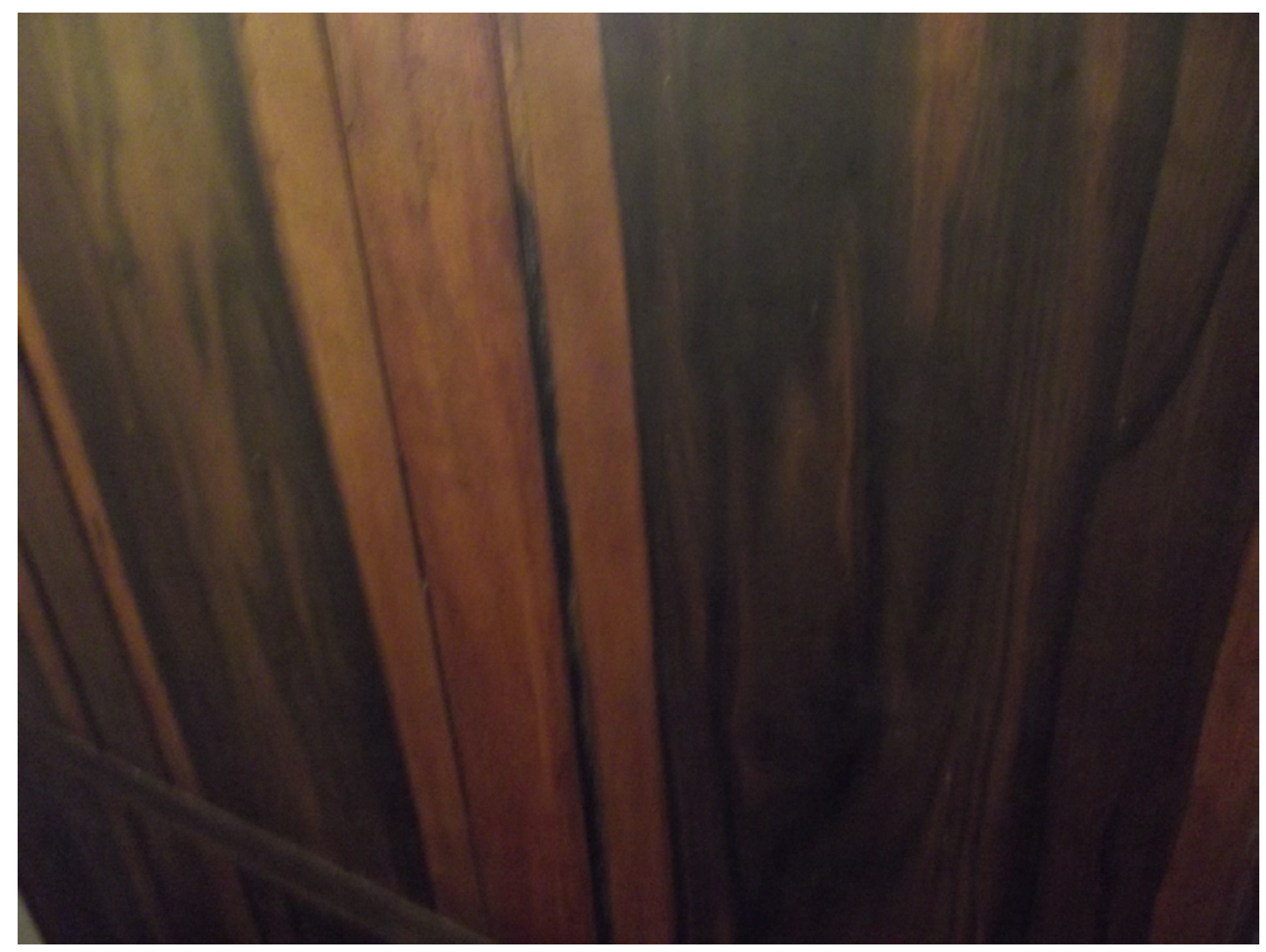

Fig. 9. Trasera de la cómoda escritorio en madera de kamagong. Antigua casa de Ramón Martínez-Labiarón, Grandas de Salime (Asturias). Foto: Ángela Ferreira Martínez.

A pesar de que este modelo de mueble, realizado en madera de alcanfor y con esta tipología no es infrecuente encontrarlo en el mercado de arte y antigüedades $^{22}$, este es el único que hemos encontrado con una trasera en esta madera. Siendo común en todos ellos que lleven una trasera en alcanfor, que es la misma madera que se utiliza para toda la estructura interior y exterior del mueble.

Aunque el establecimiento de ebanistas chinos en Filipinas realizando mobiliario se puede rastrear desde el siglo XVII, el auge de su presencia en todos los ámbitos de la producción de bienes de lujo y artes decorativas alcanza su máximo desarrollo en el siglo XVIII, con las oportunidades comerciales que ofrecía el comercio del Galeón de Manila. ${ }^{23}$ 


\section{Conclusiones}

Por todos los datos recabados podemos precisar que tenemos en Asturias una pieza de mobiliario de campaña del segundo cuarto del siglo XIX, en un estado de conservación excelente, sin ninguna modificación y que nos muestra un tipo de producción de mobiliario escasamente conocido de tipologías foráneas realizadas en territorios españoles de ultramar y que eran adquiridos por los funcionarios y militares coloniales como mobiliario de viaje que les acompañaba en sus singladuras como parte de su equipaje. También es ya un tipo de mobiliario que dejará de cumplir su función, con la modernización de los medios de transporte y la aparición de todo tipo de equipajes convertibles, tales como baúles tocadores, armario tocador, biblioteca, escritorio, archivadores de correspondencia y otra serie de sorprendentes combinaciones, incluidas camas auxiliares o de campaña.

La marca más conocida en artículos de viaje era la firma Louis Vuitton, proveedora de las principales casas reinantes ${ }^{24}$, y que rápidamente por imitación pasó a ser la preferida por la burguesía acomodada e internacional. De esta forma el mobiliario de viaje paso a ocupar un espacio definitivo e inamovible en los salones o estudios de las casas, como es el caso de esta cómoda escritorio de campaña, que durante los últimos 140 años no se ha movido del salón, allí dónde lo dejó Martínez-Labiarón en la década de 1880.

\section{NOTAS}

${ }^{1} A$ rare and imposing pair of Cuban mahogany sacristy chests second quarter $18^{\text {th }}$ century. Bonham's \& butterfields, Los Ángeles sale 16107, 8 de Septiembre de 2008, lote 408.

${ }^{2}$ Sólo en la segunda mitad del siglo XVIII se publicaron en Inglaterra más de 290 títulos de pattern books con diseños de arquitectura, interiores y mobiliario, que fueron reimpresos en América en sucesivas ediciones.

${ }^{3}$ Morrison H. Hecksher y Peter M. Kenny "English Ornaments Prints and Furniture Books in Eighteenth-Century America" en Heilbrunn Timeline of History (New York: The Metropolitan Museum of Art, 2000).

${ }^{4}$ Licenciado en Teología, ostentó el cargo de racionero, penitenciario interino y canónigo magistral de la Santa Iglesia Metropolitana de Manila.

${ }^{5}$ Roberto Blanco, "Pedro Peláez, líder del clero filipino," Hispania Sacra no. LXIII (Jul - Dic 2011): $747-782$.

${ }^{6}$ AHN: Ultramar, Filipinas, Gracia y Justicia, leg. 2255-1 del 22 de Junio de 1863. Carta del arzobispo de Manila Gregorio Melitón.

${ }^{7}$ AHN: Ultramar, Filipinas, Gracia y Justicia, leg. 2255-1 del 22 de Junio de 1863. Carta del arzobispo de Manila Gregorio Melitón.

${ }^{8}$ Según las fuentes orales trasmitidas de generación en generación en la familia Martínez Guzmán, el presbítero sobrevivió al terremoto tras esconderse debajo del altar Mayor.

${ }^{9}$ Un terremoto de intensidad X sacude Luzón del 14 al 25 de julio de 1880. El seísmo causó graves daños en Manila donde se derrumbaron muchos edificios. Se desconoce el número total de víctimas mortales. El grado de intensidad del terremoto se marcaba con números romanos antes de existir la escala Richter.

${ }^{10}$ Según las mismas fuentes orales familiares cuando Martínez-Labiarón llega a Grandas de Salime está parcialmente ciego. 
${ }^{11}$ La familia Martínez Guzmán ha seguido preservando el recuerdo de su familiar y la estancia en la que se alojó en su casa natal es conocida desde entonces como "la habitación de don Ramón”, cuya entrada está presidida por un retrato del canónigo. Dicho retrato es un óleo sobre lienzo firmado por J. Donetti.

${ }^{12}$ A partir de 1880 el Estado español saca a concurso una ruta subvencionada para cubrir las comunicaciones regulares y exclusivas entre la Península y Filipinas, siendo la Compañía Naviera del Marqués de Campo la encargada de la ruta Barcelona-Manila entre 1880-1884. La reducción de la comunicación con Filipinas a través de canal de Suez se cifra en 8 semanas aproximadamente, siendo solamente un mes el tiempo necesario para llegar a la colonia.

${ }^{13}$ Ley de Puertos, Gaceta de Madrid no. 129, 8 de mayo de 1880: 331-333.

${ }^{14}$ Registro Civil de Grandas de Salime, sección $3^{a}$, tomo 11, página 1.

${ }^{15}$ Información extraída de la página web de la Real Academia de la Historia el 13 de febrero de 2021. http://dbe.rah.es/biografias/69650/pio-pazos-y-vela-hidalgo

${ }^{16}$ Juan José Navarro, Álbum del Marqués de la Victoria (Madrid: Museo Naval, 1995).

${ }^{17}$ Alessandra Ponte et al., "From Sheraton To The Regency, en Furniture From Rococo To Art Deco. (Singapore: Evergreen-Taschen Gmbh, 2002), 466-481

${ }^{18}$ El Lignum vitae tienen una veta entre verdosa y dorada que se oscurece con el tiempo. De una gran dureza, grano denso, difícil de trabajar y con una cierta toxicidad. Pero resiste muy bien los climas tropicales, la humedad y el ataque de xilófagos y otros insectos. Sofía Rodríguez Bernis, "Lignum Vitae," en Diccionario de Mobiliario, ed. Ministerio de Cultura (Secretaria General Técnica. Subdirección General de Publicaciones, Información y Documentación 2006), 208.

19 Frances Collard, "The Regency Revival," The Journal of the Decorative Arts Society 18901940 no.8 (1984):7-18. http://www.jstor.org/stable/41806278

${ }^{20}$ Martín Jesús Imperial Tadeo Tinio, “A Tinio-Gabaldon Cabinet," Liveauctioneers. https:// www.liveauctioneers.com/item/42713465 a-tinio-gabaldon-cabinet

${ }^{21}$ Veáse por ejemplo Fulgencio F. Jun, "Sheraton-style Baliuag altar table, 19th century, narra and kamagong, Bulcan," Salcedo Auctions. https://salcedoauctions.com/twal/35/ salcedosays-the-hidden-history-in-your-furniture

${ }^{22}$ Distintas cómodas escritorio de campaña en estilo Regency realizadas por ebanistas chinos en Cantón y otras posesiones inglesas en Asia. Hanebergs Antiques, "Brass Inlaid Wood Campaign Desk," Hanebergs Antiques. http://www.hanebergsantiques.com/ catdetail.php?item $=387$

${ }^{23}$ Fulgencio F. Jun, “The Beginning," Salcedo Auctions. https://salcedoauctions.com/ twal/35/salcedosays-the-hidden-history-in-your-furniture

${ }^{24}$ La primera casa real en utilizar la firma fue la francesa. La emperatriz Eugenia de Montijo esposa de Napoleón III elige la firma Vuitton para que le confeccionase sus juegos de maletas y baúles, manteniéndose fiel a la firma a lo largo de toda su vida. 